Original article

\title{
Trauma and suicidality in war affected communities
}

\author{
J. Jankovic ${ }^{\mathrm{a}, *, \mathrm{~b}}$, S. Bremner ${ }^{\mathrm{c}}$, M. Bogic ${ }^{\mathrm{a}}$, D. Lecic-Tosevski ${ }^{\mathrm{d}}$, D. Ajdukovic ${ }^{\mathrm{e}}$, T. Franciskovic ${ }^{\mathrm{f}}$, \\ G.M. Galeazzi ${ }^{\mathrm{g}}$, A. Kucukalic ${ }^{\mathrm{h}}$, N. Morina ${ }^{i}$, M. Popovski $^{\mathrm{j}}$, M. Schützwohl ${ }^{\mathrm{k}}$, S. Priebe ${ }^{\mathrm{a}}$ \\ ${ }^{a}$ Unit for Social and Community Psychiatry, Barts and the London School of Medicine and Dentistry, Queen Mary University of London, London, UK \\ ${ }^{\mathrm{b}}$ Dudley and Walsall Mental Health Partnership NHS Trust, Dudley, UK \\ ${ }^{\mathrm{C}}$ Centre for Primary Care and Public Health, Blizard Institute, Barts and the London School of Medicine and Dentistry, Queen Mary University of London, London, UK \\ ${ }^{\mathrm{d}}$ Belgrade University School of Medicine, Belgrade, Serbia \\ ${ }^{\mathrm{e}}$ Faculty of Philosophy, University of Zagreb, Zagreb, Croatia \\ ${ }^{\mathrm{f}}$ School of Medicine, University of Rijeka, Rijeka, Croatia \\ ${ }^{\mathrm{g}}$ Department of Psychiatry, University of Modena and Reggio Emilia, Modena, Italy \\ ${ }^{\mathrm{h}}$ School of Medicine, University of Sarajevo, Sarajevo, Bosnia and Herzegovina \\ ${ }^{i}$ Department of Clinical Psychology, University of Amsterdam, Amsterdam, The Netherlands \\ ${ }^{\mathrm{j}}$ Faculty of Philosophy, University of Skopje, FYR, Macedonia \\ ${ }^{\mathrm{k}}$ Department of Psychiatry and Psychotherapy, University of Technology, Dresden, Germany
}

\section{A R T I C L E I N F O}

\section{Article history:}

Received 21 October 2011

Received in revised form 12 May 2012

Accepted 5 June 2012

Available online $\mathrm{xxx}$

\section{Keywords:}

PTSD

War

Suicide

\begin{abstract}
A B S T R A C T
Purpose: The aim was to assess whether experiences of war trauma remain directly associated with suicidality in war affected communities when other risk factors are considered.

Materials and methods: In the main sample 3313 participants from former Yugoslavia who experienced war trauma were recruited using a random sampling in five Balkan countries. In the second sample 854 refugees from former Yugoslavia recruited through registers and networking in three Western European countries. Sociodemographic and data on trauma exposure, psychiatric diagnoses and level of suicidality were assessed.

Results: In the main sample 113 participants (3.4\%) had high suicidality, which was associated with number of potentially traumatic war experiences (odds ratio 1.1) and war related imprisonment (odds ratio 3 ) once all measured risk factors were considered. These associations were confirmed in the refugee sample with a higher suicidality rate (10.2\%).

Discussion and conclusions: Number of potentially traumatic war experiences, in particular imprisonment, may be considered as a relevant risk factor for suicidality in people affected by war.
\end{abstract}

(c) 2012 Elsevier Masson SAS. All rights reserved.

\section{Introduction}

Traumatic experiences can have reverberating effects on mental health and may result in suicidal behaviour decades following the exposure [17]. Suicidality has been associated with different types of traumatic events such as combat experience [12], sexual assault, having witnessed someone being seriously injured or killed [11], natural disasters [16] and childhood trauma, in particular sexual abuse [23].

The aetiological route between the traumatic experience and suicidality remains unclear, with most studies suggesting that a psychological trauma contributes to the development of psychiatric disorders such as psychosis, depression, personality disorder, posttraumatic stress disorder (PTSD) and substance misuse

\footnotetext{
* Corresponding author. Unit for Social and Community Psychiatry, Queen Mary University of London, Academic Unit, Newham Centre for Mental Health, Cherry Tree Way, Glen Road, London, E13 8SP, United Kingdom. Tel.: +44 02075404 210; fax: +4402075402976.

E-mail address: j.jankovic@qmul.ac.uk (J. Jankovic).
}

which in turn increase suicidality. For example, studies on suicidal attempts amongst both community and treatment seeking samples of Vietnam veterans [12,13] have shown that general psychiatric disorders contributed directly to attempted suicide whilst the contribution of traumatic exposure was indirect, via its effect on the development of psychiatric disorders. Similar results were shown in a study on Norwegian male peacekeepers [36]. Suicidality in war veterans and peacekeepers has been explored in previous research; however studies looking into effects of war experiences on suicidality in community samples, i.e. including a large proportion of civilians, have been scarce.

Measurement of trauma has been a complex problem with both cumulative trauma and type of events being suggested as important. A dose-response effect between traumatic injury and suicide risk has been postulated [6] as well as certain high risk traumatic events such as incarceration and domestic violence.

The protracted war in former Yugoslavia during the 1990s resulted in crimes against civilians, which included worst atrocities seen in Europe since World War II [33]. The traumatic experiences that people in former Yugoslavia encountered during 
the war included participating in active combat, imprisonment, torture, rape, the destruction of their homes, witnessing killings or atrocities and being wounded or beaten during forced displacements from their towns [3]. These traumatic events led to a number of mental health problems including suicidality [21].

In this study we aimed to assess whether potentially traumatic war experiences (both cumulative experiences and specific types of trauma) remain directly associated with suicidality in war affected communities when trauma before and after the war as well as relevant sociodemographic and clinical risk factors are taken into account.

\section{Materials and methods}

The main community sample was obtained through a multicentre survey in five countries - Bosnia and Herzegovina, Croatia, Kosovo (a province of Serbia at the time of the data collection), Macedonia (Former Yugoslavian Republic of Macedonia), and Serbia. The rationale and methods have been described in detail elsewhere $[25,27]$. A multistage probabilistic sampling frame and random walk technique were used. Firstly, administrative areas that had been directly exposed to war activities were identified of which approximately $20 \%$ were randomly chosen (fifteen in total). Forty-nine localities in these areas were randomly selected and streets were randomly identified with every fourth household being selected.

The second sample was obtained by interviewing refugees from former Yugoslavia currently residing in the three Western European countries with the highest number of immigrants in the 1990s i.e. Germany, Italy, and the United Kingdom (UK) [10]. They were recruited with a combination of random and nonrandom sampling approaches.

In Germany and Italy, potential participants were identified through resident registers. They were randomly selected and sent an invitation to participate. In the UK, potential participants were contacted through community organizations that mailed invitations to participate to all their members. In addition, in all three countries, a snowball sample was recruited through the first group of respondents who were asked to provide contact details of other refugees from former Yugoslavia. Participants were also recruited at various cultural events for refugees.

Inclusion criteria for both samples were that a participant was born within the territory of former Yugoslavia; was between 18 and 65 years old; experienced at least one war related potentially traumatic event for which a screening list of 20 stressful war related events was used (this was to ensure that all participants really had experienced a potentially traumatic war events); experienced the last war relate event at or after 16 years of age; had no severe learning difficulty and no mental impairment due to a brain injury or other organic cause.

The study has been approved by relevant ethic committees in each country and written consent form was obtained from all participants. This study was funded by a grant from the European Commission (contract number INCOCT-2004-509175).

\subsection{Procedures and measures}

All interviews were conducted face-to-face between January 2005 and November 2006. A structured questionnaire was used to obtain participants' age, gender, educational level, living arrangements and employment status. The history of twenty-four potentially traumatic experiences before, during and after the war was assessed using a specifically amended version of the Life Stressor Checklist-Revised [41]. Cumulative scores for pre-war, war and post-war experiences were calculated by summarising different types of traumatic events that each participant has experienced.

Current mental disorders including suicidality were assessed using the MINI International Neuropsychiatric Interview [31] which is a structured diagnostic interview assessing the symptom criteria used in the Diagnostic and Statistical Manual of Mental Disorders IV [2].

Studies have shown that the instrument is valid when measured against the longer Composite International Diagnostic Interview (CIDI) and the Structured Clinical Interview for DSM-III$R$ Patients (SCID-P) $[19,30]$ and reliable in various cultures [28]. It has been used successfully as a diagnostic tool to identify populations with mental disorders in war affected populations [22].

The MINI International Neuropsychiatric Interview was used to assess suicidality in this study. Five questions on MINI refer to the past month:

- having thoughts of being better off dead or wishing to be dead;

- wishing to harm oneself;

- having thoughts of suicide;

- having a suicidal plan;

- having made a suicide attempt.

In addition one question refers to a lifetime suicide attempt.

In order to classify current suicidality as dichotomous variable (and in the absence of an existing dichotomous "cut off" point) we used a criteria for clinically significant suicidality i.e. that a person is classified as having a "high" suicidality if they report that in the past month they had thoughts of suicide and/or suicidal plans and/or attempted a suicide. Those who had only thoughts of being better off dead/wishing to be dead or wishing to harm themselves in the past month (without having thoughts or plans of suicide or attempting a suicide) were classified as having "low" suicidality.

All participating interviewers received training in the assessments used in the survey. Two mock interviews were used to assess a rating agreement among interviewers. Among 251 items, the mean agreement rate across two sessions was $90.2 \%$ (agreement being defined when all interviewers gave the same answer for an item). Relevant national ethic committees approved the study and written informed consent was obtained from all participants.

\subsection{Statistical analysis}

Descriptive statistics were used to report sociodemographic and clinical characteristics of the sample. Unifactorial logistic regressions were conducted to assess relationships between suicidality and variables that are known to be associated with suicidality, namely age, gender, unemployment, living alone and clinical characteristics (major depression, psychotic disorder, substance misuse and PTSD). Further unifactorial logistic regressions were conducted between suicidality and the number of potentially traumatic experiences before, during and after the war, between suicidality and single potentially traumatic war events, and between suicidality and childhood trauma.

Suicide rates between Eastern European (including Balkan) countries show striking differences [42] for which there is no sufficient explanation [38]. Therefore, as we were interested in the relationship between traumatic events and suicidality in general rather than in country-specific terms, we adjusted for these differences in suicidality rates between countries by using a fixed effects logistic regression model (with countries as fixed effects) for analyses within the main sample. 
The analyses were based on the sample with the complete information on each variable. In the main sample, analyses using a fixed effects logistic regression model were applied in order to assess whether war experiences remained significantly associated with suicidality when the findings were adjusted for the influence of relevant sociodemographic factors, clinical variables and cumulative trauma scores. Two analyses were conducted, the first one with the number of potentially traumatic war experiences as a potential predictor variable, and the second one testing the predictive value of single specific experiences. In the first analysis, age, gender, unemployment and living alone were entered in the first block, and in the next step variables not significant at the $10 \%$ level were removed before the second block of clinical characteristics (major depression, psychotic disorder, substance misuse and PTSD) were entered. Again variables not significant at $10 \%$ level were removed before the third block was entered. The third block consisted of cumulative score of pre-war, post-war and traumatic events during the war. For the second analysis, after variables not significant at the $10 \%$ level were removed, the number of potentially traumatic war experiences was replaced by single potentially traumatic events that showed unifactorial associations with suicidality (Spearman's correlation coefficient $\geq 0.1$ ). Four out of 24 potentially traumatic events met this criterion and therefore only these four events were included in the second analysis. The final model was obtained after removing variables not significant at the $10 \%$ level.

Multicollinearity among potential predictor variables was assessed using the variance inflation factor (VIF) statistic from the equivalent linear regression model and it did not indicate serious multicollinearity (VIF not exceeding 10). Statistical modelling was carried out using Stata version 10.1 [34].

Because relative risk (as opposed to odds ratio) is sometimes seen as a preferred measure of risk we attempted to model the relative risk of suicidality but this was not possible (models did not converge as predicted probabilities can be outside the range of 0 to 1 ). Given the rarity of suicidality, the odds ratios will be a reasonable approximation to the relative risks. This holds for prevalence of up to $10 \%$ [43]. In the refugees, the prevalence only just exceeded $10 \%$.

The two models obtained in the main sample were tested in the second sample of refugees in Western European countries. Variability in suicidality rates was taken into account by using fixed effects logistic regression models (with countries as a fixed effects).

\section{Results}

Table 1 presents sociodemographic, clinical and trauma related characteristics of the main sample and the refugee sample.

In the main sample, a total of 3313 participants were interviewed across the five Balkan countries. Across all countries, $70.1 \%$ of the eligible participants were interviewed. In Bosnia and Herzegovina 640 participants were interviewed, in Croatia 727, in Serbia 637, in Kosovo 648 and in Macedonia 661 participants.

Out of 113 (3.4\%) participants who had high suicidality, 24 $(0.7 \%)$ attempted suicide in their life and 74 (2.2\%) attempted suicide within the past month. As expected, suicidality varied across countries with the highest rates in Croatia (5.8\%), then in Bosnia and Herzegovina (4.2\%), Serbia (4\%), Kosovo (2.2\%) and the lowest rates in Macedonia (0.8\%).

In the main sample, a large proportion of participants was unemployed or retired (around 60\%) and had more than primary school education. A small minority lived alone, about a fifth of participants had major depression and about a fifth had PTSD.
Table 1

Sociodemographic, clinical and trauma related characteristics of both samples.

\begin{tabular}{|c|c|c|}
\hline & $\begin{array}{l}n=3313 \\
\text { Main sample }\end{array}$ & $\begin{array}{l}n=854 \\
\text { Refugee sample }\end{array}$ \\
\hline Mean age (SD) & $42.5(12.1)$ & $41.6(10.8)$ \\
\hline $\begin{array}{l}\text { Education level attained, } n(\%) \\
\text { None or primary education } \\
\text { Secondary school } \\
\text { Vocational/tertiary }\end{array}$ & $\begin{array}{r}1007(30.4) \\
1618(48.8) \\
688(20.8)\end{array}$ & $\begin{array}{l}188(22.0) \\
354(41.5) \\
312(36.5)\end{array}$ \\
\hline $\begin{array}{l}\text { Gender, } n(\%) \\
\text { Female } \\
\text { Male }\end{array}$ & $\begin{array}{l}1783(53.8) \\
1529(46.2)\end{array}$ & $\begin{array}{l}438(51.3) \\
416(48.7)\end{array}$ \\
\hline $\begin{array}{l}\text { Living status, } n(\%) \\
\text { Living alone } \\
\text { Living with someone }\end{array}$ & $\begin{array}{c}177(5.3) \\
3136(94.7)\end{array}$ & $\begin{array}{r}96(11.2) \\
758(88.8)\end{array}$ \\
\hline $\begin{array}{l}\text { Employment status, } n(\%) \\
\text { Employed/in education } \\
\text { Unemployed (including retired) }\end{array}$ & $\begin{array}{l}1329(40.1) \\
1984(59.9)\end{array}$ & $\begin{array}{l}469(54.9) \\
385(45.1)\end{array}$ \\
\hline $\begin{array}{l}\text { Psychiatric diagnosis (MINI), } n \text { (\%) } \\
\text { Suicidality-high risk } \\
\text { Posttraumatic stress disorder } \\
\text { Psychotic disorder } \\
\text { Substance misuse } \\
\text { Major depression }\end{array}$ & $\begin{aligned} 116 & (3.5) \\
665 & (20.1) \\
40 & (1.2) \\
33 & (1.0) \\
657 & (19.8)\end{aligned}$ & $\begin{aligned} 87 & (10.2) \\
283 & (33.1) \\
11 & (1.3) \\
4 & (0.5) \\
292 & (34.2)\end{aligned}$ \\
\hline $\begin{array}{l}\text { Number of pre-war potentially } \\
\text { traumatic events } \\
\text { Mean (SD) }\end{array}$ & $0.7(1.1)$ & $1.1(1.3)$ \\
\hline $\begin{array}{l}\text { Number of war potentially } \\
\text { traumatic events } \\
\text { Mean (SD) }\end{array}$ & $4.2(2.8)$ & $6.8(3.6)$ \\
\hline $\begin{array}{l}\text { Number of post-war potentially } \\
\text { traumatic events } \\
\text { Mean (SD) }\end{array}$ & $0.5(0.8)$ & $1.1(1.3)$ \\
\hline
\end{tabular}

In the second, refugee sample, 854 refugees were recruited. Across the three countries, 627 participants were recruited by random techniques (overall participation rate was $52.9 \%$ ). The remaining 227 participants were recruited via networking and snowball sampling. Overall 255 participants were recruited in Germany, 297 in Italy, and 302 in the UK.

Out of 854 refugees, 87 (10.2\%) had high suicidality. Fifty-nine (6.9\%) had attempted suicide in their lifetime, and six $(0.7 \%)$ had attempted suicide within the past month. The highest rate of suicidality was in Germany (19.6\%), whilst rates in the UK (6.3\%) and Italy (6\%) were lower.

As shown in Table 1 , in comparison to the main sample, refugees living in Western European countries had higher prevalence of PTSD and Major Depression and had experienced more potentially traumatic events during the war and after the war than participants from the Balkan countries in the main sample.

Table 2 shows the frequency of single war experiences for both samples and correlation coefficients of war experiences with suicidality for the main sample.

In both samples the most frequent potentially traumatic experience before and after the war was the sudden death of a dear person whilst shelling was the commonest event during the war.

In the main sample, the war experiences most highly correlated with suicidality were imprisonment, combat, serious injury and witnessing of assault, murder or death. One hundred and sixteen participants (3.6\%) had experienced childhood trauma (sexual or non-sexual abuse or death of a dear person before the age of 16), but the association with suicidality was not significant $(\mathrm{OR}=1.53$, CI [0.66-3.56], $P=0.322$, Spearman's correlation coefficient 0.017 , $P=0.318$ ). 
Table 2

Number (and percentage) of participants who experienced potentially traumatic events before, during and after the war and Spearman's correlation coefficient (in square brackets) for relationship of individual war events with suicidality for the main sample.

\begin{tabular}{|c|c|c|c|c|c|c|}
\hline Type of traumatic event & $\begin{array}{l}\text { Pre-war events } \\
\text { Main sample }\end{array}$ & $\begin{array}{l}\text { War events } \\
\text { Main sample }\end{array}$ & $\begin{array}{l}\text { Post-war events } \\
\text { Main sample }\end{array}$ & $\begin{array}{l}\text { Pre-war events } \\
\text { Refugee sample }\end{array}$ & $\begin{array}{l}\text { War events } \\
\text { Refugee sample }\end{array}$ & $\begin{array}{l}\text { Post-war events } \\
\text { Refugee sample }\end{array}$ \\
\hline Serious accident, fire, or explosion & $409(12.3)$ & $200(6)\left[0.050^{* *}\right]$ & $191(5.8)$ & $162(19)$ & $45(5.3)$ & $100(11.7)$ \\
\hline Natural disaster & $317(9.6)$ & $36(1.1)[0.028]$ & $118(3.6)$ & $206(24.1)$ & $12(1.4)$ & $51(6.0)$ \\
\hline $\begin{array}{l}\text { Non-sexual assault by someone } \\
\text { they knew }\end{array}$ & $82(2.5)$ & $79(2.4)[0.025]$ & $59(1.8)$ & $53(6.2)$ & $137(16.0)$ & $44(5.2)$ \\
\hline Non-sexual assault by stranger & $84(2.5)$ & $241(7.3)\left[0.069^{* * *}\right]$ & $78(2.4)$ & $53(6.2)$ & $315(36.9)$ & $68(8.0)$ \\
\hline Sexual assault by someone they knew & $19(0.6)$ & $4(0.1)\left[0.041^{*}\right]$ & $6(0.2)$ & $18(2.1)$ & $13(1.5)$ & $6(0.7)$ \\
\hline Sexual assault by stranger & $10(0.3)$ & $8(0.2)[0.025]$ & $2(0.1)$ & $10(1.2)$ & $31(3.6)$ & $5(0.6)$ \\
\hline Imprisonment & $40(1.2)$ & $139(4.2)\left[0.110^{* * * *}\right]$ & $22(0.7)$ & $28(3.3)$ & $166(19.4)$ & $36(4.2)$ \\
\hline Life threatening illness & $211(6.4)$ & $105(3.2)\left[0.080^{* * *}\right]$ & $233(7.0)$ & $53(6.2)$ & $31(3.6)$ & $88(10.3)$ \\
\hline Sudden death of a dear person & $704(21.2)$ & $290(8.8)\left[0.042^{*}\right]$ & $758(22.9)$ & $231(27)$ & $99(11.6)$ & $276(32.3)$ \\
\hline Lack of food or water & $33(1.0)$ & $1222(36.9)\left[0.053^{* *}\right]$ & $24(0.7)$ & $14(1.6)$ & $454(53.2)$ & $31(3.6)$ \\
\hline Ill without access to medical care & $12(0.4)$ & $274(8.3)\left[0.088^{* * * *}\right]$ & $48(1.4)$ & $11(1.3)$ & $184(21.5)$ & $41(4.8)$ \\
\hline Lack of shelter & & $1694(51.1)\left[0.089^{* * * *}\right]$ & & & $549(64.3)$ & \\
\hline Expelled from home under threat & & $1267(38.2)[0.016]$ & $5(0.2)$ & & $402(47.1)$ & $7(0.8)$ \\
\hline Combat & & $544(16.4)\left[0.132^{* * * *}\right]$ & & & $192(22.5)$ & \\
\hline Shelling or bombardment & & $2798(84.5)[0.016]$ & & & $725(84.9)$ & \\
\hline Mine explosion & & $233(7)\left[0.053^{* *}\right]$ & $19(0.6)$ & & $81(9.5)$ & $5(0.6)$ \\
\hline Siege & & $1329(40.1)\left[0.034^{*}\right]$ & & & $506(59.3)$ & \\
\hline Serious injury & $112(3.4)$ & $226(6.8)\left[0.114^{* * * *}\right]$ & $48(1.4)$ & $40(4.7)$ & $91(10.7)$ & $32(3.7)$ \\
\hline Witnessed assault, murder or death & $102(3.1)$ & $791(23.9)\left[0.104^{* * * *}\right]$ & $78(2.4)$ & $34(4)$ & $422(49.4)$ & $14(1.6)$ \\
\hline $\begin{array}{l}\text { Learned about murder or death of a } \\
\text { dear person }\end{array}$ & $80(2.4)$ & $1187(35.8)\left[0.051^{* *}\right]$ & $91(2.7)$ & $22(2.6)$ & $502(58.8)$ & $102(11.9)$ \\
\hline $\begin{array}{l}\text { Disappearance or kidnapping of a } \\
\text { dear person }\end{array}$ & $33(1.0)$ & $579(17.5)[-0.003]$ & $20(0.6)$ & $7(0.8)$ & $304(35.6)$ & $25(2.9)$ \\
\hline Torture & $46(1.4)$ & $192(5.8)\left[0.089^{* * *}\right]$ & $14(0.4)$ & $18(2.1)$ & $202(23.7)$ & $15(1.8)$ \\
\hline Being lost & $20(0.6)$ & $287(8.7)\left[0.096^{* * * *}\right]$ & $18(0.5)$ & $4(0.5)$ & $160(18.7)$ & $15(1.8)$ \\
\hline Kidnapped & $7(0.2)$ & $100(3)\left[0.093^{* * *}\right]$ & $3(0.1)$ & $5(0.6)$ & $147(17.2)$ & $8(0.9)$ \\
\hline
\end{tabular}

${ }^{*} P<0.05$.

${ }^{* *} P \leq 0.01$.

${ }^{* * *} P \leq 0.001$.

Tables 3 and 4 present results from unifactorial and multifactorial logistic regression analyses with suicidality as a dependent variable in the main sample.

In the first multifactorial logistic regression, the number of potentially traumatic war events remained significantly associated with suicidality when other significant risk factors (sociodemographic characteristics of gender, unemployment and living alone, clinical characteristics of depression, PTSD and psychotic disorder and cumulative score of pre-war potentially traumatic experiences) were taken into account. The odds ratio was 1.11, indicating that increase in one unit (i.e. each experienced war event listed in Table 2 ) increases the odds of suicidality by 1.1 times. Although the magnitude appears to be small, there are 24 of these war events and on average each participant in the main sample experienced more than four events, therefore cumulatively this increase in odds can be clinically significant.

The second multifactorial logistic regression considered single war experiences instead of a cumulative score. The final model shows that war related imprisonment remains significantly associated with suicidality several years after the war even when the findings have been adjusted for the influence of potentially traumatic pre-war experiences, sociodemographic and clinical characteristics. The odds ratio was 3.0 indicating that those participants who were imprisoned had a three times the odds of being suicidal comparing to the ones who were not imprisoned.

Table 3

Results of unifactorial and multifactorial logistic regression for cumulative score of war trauma in the main sample.

\begin{tabular}{|c|c|c|c|c|c|c|c|c|c|c|c|c|}
\hline \multirow[t]{2}{*}{$\begin{array}{l}\text { Independent } \\
\text { variables }\end{array}$} & \multicolumn{3}{|c|}{ Unifactorial } & \multicolumn{3}{|c|}{$\begin{array}{l}\text { Multifactorial 1st block first } \\
\text { analysis }\end{array}$} & \multicolumn{3}{|c|}{$\begin{array}{l}\text { Multifactorial 2nd block first } \\
\text { analysis }\end{array}$} & \multicolumn{3}{|c|}{$\begin{array}{l}\text { Multifactorial 3rd block first } \\
\text { analysis }\end{array}$} \\
\hline & OR & $95 \% \mathrm{CI}$ for OR & $P$ value & OR & $95 \% \mathrm{CI}$ for OR & $P$ value & OR & $95 \% \mathrm{CI}$ for OR & $P$ value & OR & $95 \% \mathrm{CI}$ for $\mathrm{OR}$ & $P$ value \\
\hline Female gender & 0.52 & $0.35-0.76$ & 0.001 & 0.46 & $0.31-0.67$ & $<0.001$ & 0.46 & $0.30-0.70$ & $<0.001$ & 0.56 & $0.35-0.87$ & 0.011 \\
\hline Unemployed & 2.55 & $1.62-4.03$ & $<0.001$ & 2.89 & $1.79-4.66$ & $<0.001$ & 1.86 & $1.12-3.08$ & 0.016 & 1.75 & $1.05-2.92$ & 0.031 \\
\hline Living alone & 3.11 & $1.80-5.41$ & $<.0001$ & 2.02 & $1.13-3.60$ & 0.018 & 1.88 & $0.99-3.57$ & 0.053 & 1.73 & $0.91-3.31$ & 0.087 \\
\hline Age & 1.03 & $1.01-1.04$ & 0.002 & 1.01 & $0.99-1.02$ & 0.425 & & & & & & \\
\hline PTSD & 10.83 & $7.15-16.40$ & $<0.001$ & & & & 4.64 & $2.85-7.55$ & $<0.001$ & 3.93 & $2.38-6.49$ & $<0.001$ \\
\hline Psychotic disorder & 6.40 & $2.77-14.80$ & $<0.001$ & & & & 5.4 & $2.08-16.64$ & 0.001 & 4.35 & $1.46-12.93$ & 0.008 \\
\hline Major depression & 8.81 & $5.88-13.22$ & $<0.001$ & & & & 4.75 & $2.92-7.73$ & $<0.001$ & 4.20 & $2.57-6.88$ & $<0.001$ \\
\hline Substance misuse & 2.88 & $0.87-9.59$ & 0.084 & & & & 0.59 & $0.13-2.78$ & 0.507 & & & \\
\hline $\begin{array}{c}\text { Number of pre-war } \\
\text { traumatic events }\end{array}$ & 1.45 & $1.29-1.63$ & $<0.001$ & & & & & & & 1.22 & $1.05-1.41$ & 0.011 \\
\hline $\begin{array}{l}\text { Number of post-war } \\
\text { traumatic events }\end{array}$ & 1.57 & $1.31-1.88$ & $<0.001$ & & & & & & & 1.10 & $0.88-1.38$ & 0.412 \\
\hline $\begin{array}{l}\text { Number of war } \\
\text { traumatic events }\end{array}$ & 1.27 & $1.20-1.35$ & $<0.001$ & & & & & & & 1.11 & $1.03-1.21$ & 0.009 \\
\hline
\end{tabular}

1 indicates presence of a characteristic described in independent variable whilst 0 indicates absence of that condition, e.g. 1 indicates female gender whilst 0 indicates male gender. OR: odds ratio; CI: confidence interval; PTSD: posttraumatic stress disorder. 
Table 4

Results of multifactorial logistic regression for individual war traumatic events in the main sample.

\begin{tabular}{|c|c|c|c|c|c|c|}
\hline & \multicolumn{3}{|c|}{ Multifactorial 3rd block second analysis } & \multicolumn{3}{|c|}{$\begin{array}{l}\text { Multifactorial 3rd block second analysis revised } \\
\text { (excluding non-significant variables) }\end{array}$} \\
\hline & OR & $95 \% \mathrm{CI}$ for $\mathrm{OR}$ & $P$ value & OR & $95 \% \mathrm{CI}$ for OR & $P$ value \\
\hline Female gender & 0.69 & $0.40-1.20$ & 0.185 & & & \\
\hline Unemployed & 1.72 & $1.03-2.87$ & 0.039 & 1.67 & $1.01-2.76$ & 0.048 \\
\hline Living alone & 2.00 & $1.05-3.83$ & 0.036 & 1.96 & $1.04-3.70$ & 0.038 \\
\hline PTSD & 4.11 & $2.50-6.75$ & $<0.001$ & 4.72 & $2.91-7.65$ & $<0.001$ \\
\hline Psychotic disorder & 4.83 & $1.60-14.60$ & 0.005 & 4.82 & $1.66-14.01$ & 0.004 \\
\hline Major depression & 4.31 & $2.64-7.02$ & $<0.001$ & 4.29 & $2.65-6.93$ & $<0.001$ \\
\hline \multicolumn{7}{|l|}{ Substance misuse } \\
\hline Number of pre-war traumatic events & 1.23 & $1.05-1.43$ & 0.009 & 1.20 & $1.03-1.41$ & 0.018 \\
\hline War- Imprisonment & 2.27 & $1.18-4.37$ & 0.014 & 3.00 & $1.60-5.61$ & 0.001 \\
\hline War- Combat & 1.55 & $0.82-2.94$ & 0.174 & & & \\
\hline War- Serious injury & 1.20 & $0.66-2.20$ & 0.555 & & & \\
\hline War-Witnessed assault, murder or death & 1.22 & $0.74-2.01$ & 0.434 & & & \\
\hline
\end{tabular}

1 indicated presence of a characteristic described in independent variable whilst 0 indicates absence of that condition, e.g. 1 indicates female gender whilst 0 indicates male gender. OR: odds ratio; CI: confidence interval; P: P value; PTSD: posttraumatic stress disorder.

When the final models obtained in the main sample were tested in the second, refugee sample, both the number of potentially traumatic war experiences and war related imprisonment remained significantly associated with suicidality (Table 5) although the magnitude of the odds ratio was lower.

\section{Discussion}

\subsection{Main findings}

The number of potentially traumatic war experiences and war related imprisonment are associated with a higher level of suicidality, independently of other traumatic experiences, and sociodemographic and clinical risk factors in community samples several years after the war. The results suggest possibility of a direct link between traumatic war experiences and suicidality and indicate that a higher number of potentially traumatic experiences during the war as well as a specific event, i.e. imprisonment, may be considered as relevant risk factors for suicidality in people affected by war.

In terms of other risk factors major depression and PTSD remain consistently associated with high suicidality several years following war even when other relevant variables are controlled for in a multivariable analysis.

\subsection{Strengths}

Participants were randomly chosen for the main sample and the same sampling method has been applied across all five countries. This is one of the largest community based studies assessing suicidality and mental disorders in people affected by war. The results held true in the refugee sample despite different levels of suicidality.

\subsection{Limitations}

The study also has several limitations. The reporting of past experiences may have been influenced by recall bias [32]. The study is cross sectional and therefore can demonstrate association but not causation. In terms of psychiatric diagnoses, borderline personality disorder, which is associated both with suicidality and childhood trauma has not been assessed. However, in many people with borderline personality disorder who are suicidal, other clinical characteristics such as major depression, substance misuse and PTSD are present and these have been accounted for in the main analysis in this study. A significant limitation is that the refugee sample was recruited using both random and non-random techniques, which can introduce selection bias. Therefore we analysed the two samples separately and used the refugee sample to explore whether findings from the analysis of the main random

Table 5

Results of multifactorial logistic regression in the refugee sample.

\begin{tabular}{|c|c|c|c|c|c|c|}
\hline & \multicolumn{3}{|c|}{ Multifactorial analysis with cumulative war trauma } & \multicolumn{3}{|c|}{ Multifactorial analysis with individual war traumatic event } \\
\hline & OR & $95 \% \mathrm{CI}$ for OR & $P$ & OR & $95 \% \mathrm{CI}$ for $\mathrm{OR}$ & $P$ \\
\hline Female gender & 1.24 & $0.75-2.05$ & 0.398 & & & \\
\hline Unemployed & 0.90 & $0.51-1.59$ & 0.711 & 0.89 & $0.50-1.59$ & 0.691 \\
\hline Living alone & 1.86 & $0.92-3.74$ & 0.083 & 1.77 & $0.88-3.56$ & 0.108 \\
\hline \multicolumn{7}{|l|}{ Age } \\
\hline PTSD & 2.45 & $1.34-4.47$ & 0.003 & 2.68 & $1.49-4.84$ & 0.001 \\
\hline Psychotic disorder & 3.53 & $0.87-14.29$ & 0.077 & 3.61 & $0.87-14.94$ & 0.077 \\
\hline Major depression & 4.15 & $2.32-7.41$ & $<0.001$ & 4.31 & $2.41-7.70$ & $<0.001$ \\
\hline \multicolumn{7}{|l|}{ Substance misuse } \\
\hline $\begin{array}{c}\text { Number of pre-war } \\
\text { traumatic events }\end{array}$ & 1.08 & $0.90-1.30$ & 0.411 & 1.08 & $0.90-1.30$ & 0.392 \\
\hline \multicolumn{7}{|l|}{$\begin{array}{l}\text { Number of post-war } \\
\text { traumatic events }\end{array}$} \\
\hline $\begin{array}{l}\text { Number of war } \\
\text { traumatic events }\end{array}$ & 1.08 & $1.00-1.16$ & 0.047 & & $\mathrm{~N} / \mathrm{A}$ & \\
\hline War- Imprisonment & & $\mathrm{N} / \mathrm{A}$ & & 1.78 & $1.02-3.10$ & 0.042 \\
\hline
\end{tabular}

1 indicated presence of a characteristic described in independent variable whilst 0 indicates absence of that condition, e.g. 1 indicates female gender whilst 0 indicates male gender. N/A: non-applicable; PTSD: posttraumatic stress disorder. 
sample are replicated in this second sample. Another limitation is that certain types of experiences that are culturally potentially stigmatising such as sexual abuse and substance misuse may have been underreported.

\subsection{Comparison with literature}

In our sample $3.4 \%$ of participants in the Balkan community had high suicidality within the past month. The rate was higher for refugees interviewed in Western European countries (10.2\%). Comparing prevalence rates of suicidality across different studies may be more difficult than comparing rates of well defined mental disorders since the prevalence of suicidal ideation significantly varies across countries [37] and different cut off points for 'dichotomising' suicidality have been defined. A community survey of the general population in the USA [15] showed that in 20012003 , the 12 -month prevalence of suicidal ideation was 3.3\% and the prevalence of suicidal plans $1 \%$ in the year before the interview, which is lower than the prevalence in our study. However, the magnitude of the difference is difficult to assess, since the studies used different time frames and in our study suicidality was assessed only within the past month. Clinical samples of traumatised individuals show much higher rates, even as high as $82.6 \%$ in a sample of Vietnam veterans undergoing psychotherapy [18].

In our study, the prevalence of suicidality was almost three times higher in the refugee sample compared to the main sample. This could be partly explained by a higher level of psychopathology and higher number of traumatic war experiences. For example imprisonment was almost five times more common in the second sample. Participants in the second sample were all refugees and had experienced number of acculturation and migration stressors in addition to war trauma, which could also contribute to the higher level of suicidality and other mental health problems in this sample. Lipsicas et al. [20] point to difficulties in the acculturation and integration process as contributing factors to suicide attempt rates in immigrants.

Whilst some participants in the main sample had also experienced forced migration, they resettled in the Balkan countries and therefore acculturation stressors were less significant as compared to those resettled in Western European countries.

With respect to the association between traumatic experiences and suicidality, the link between the cumulative war experiences and suicidality is consistent with a proposed 'dose-response effect' [6]. Similar associations have been observed between traumatic experiences and social functioning [29], and between traumatic experiences and mental illness, for example a population-based study on Vietnamese refugees [35] indicated that respondents who had been exposed to one or two trauma categories were twice as likely as those with no exposure to have a mental illness, whilst those who had been exposed to three or more trauma categories had an eight-fold increase in risk.

Imprisonment during the war is a potentially severe trauma. Participants, who were imprisoned, were more likely to have high suicidality several years after the war than those who did not have that experience. This is in line with studies suggesting that events such as confinement in concentration camps [8] torture $[4,8]$ and being kidnapped are particularly likely to lead to mental disorders such as major depression and PTSD.

Our study results add to the above findings, as they emphasise not only an association between war imprisonment and suicidality, but also that this association remains significant even when clinical disorders are controlled for. Thus, the experience of war related imprisonment appears to increase the risk of suicidality several years later, independently of the influence of mental disorders. The magnitude of the effect appears to be clinically significance. War related imprisonment, in particular during the war in former Yugoslavia often contained elements of human rights violations. Experiences of human rights violations might particularly affect an individual's trust in the reliability of societal values and rules, confidence in human relationships, and belief in a predictable and positive future [26]. This is all likely to be associated with hopelessness and ideas of ending one's life. Ajdukovic and Corkalo [1] described deep psychological injury and high levels of distrust between community members from two ethnic groups 11 years after the war. These were attributed to the failure of interethnic friends and neighbours to forewarn each other about imminent life threatening danger and to provide protection or support at the critical times. Research into psychological explanations of suicidality should consider cognitive processes of entrapment, defeat and hopelessness/helplessness $[24,39,40]$. One may hypothesise that such processes play a role in mediating the association between imprisonment and suicidality several years later.

Our data show a strong link between PTSD and depression with suicidality, which is consistent with other research. In a community survey [9] patients with PTSD were found to be 14.9 times more likely to attempt suicide than subjects without PTSD. The lifetime prevalence of suicide attempts in major depression is approximately 16\% [7]. It appears that the relationship between PTSD and depression is reciprocal [24], as depression appears to exacerbate the effect of traumatic events [14] and PTSD increases susceptibility to major depression [5], whilst both disorders are independently associated with higher suicidality.

\section{Conclusion}

Our results imply that suicidality may be considered to be a significant health consequence of war. The main clinical implication of these results is that potentially traumatic war experiences as well as specific types of such experiences may be considered as an independent risk factor for suicidality in people affected by war. Since the association is not fully explained by the existence of mental disorders, past traumatic war experiences need to be recorded specifically in the assessment of suicidality, and impact of these events explored in treatment of suicidality.

In-depth studies using qualitative methods may be required to further explore and understand the processes linking traumatic war experiences, and in particular imprisonment, with later suicidality.

\section{Disclosure of interest}

The authors declare that they have no conflicts of interest concerning this article.

\section{Acknowledgement}

Role of Funding Source: This study was funded by a grant from the European Commission (contract number INCOCT-2004509175). The funders had no role in study design, data collection and analysis, decision to publish, or preparation of the manuscript.

The authors would like to thank all the participants in the CONNECT study and all the researchers who helped with collecting the data.

\section{References}

[1] Ajdukovic D, Corkalo D. Trust and betrayal in war. In: Stover E, Weinstein HM editors. My neighbour, my enemy - Justice and community in the aftermath of mass atrocity. Cambridge: Cambridge University Press; 2004. p. 287-302. 
[2] American Psychiatric Association. Diagnostic and statistical manual of mental disorders, 4th ed, Washington, DC: American Psychiatric Association; 1994.

[3] Arcel L, Simunkovic-Tocilj G. War, Violence, Trauma and the Coping Process. Zagreb: Nakladnistvo Limun; 1998.

[4] Basoglu M, Livanou M, Crnobaric C, Franciskovic T, Suljic E, Duric D, et al. Psychiatric and cognitive effects of war in former Yugoslavia: association of lack of redress for trauma and posttraumatic stress reactions. JAMA 2005;294:580-90.

[5] Breslau N, Davis GC, Peterson EL, Schultz L. Psychiatric sequelae of posttraumatic stress disorder in women. Arch Gen Psychiatry 1997;54:81-7.

[6] Bullman TA, Kang HK. Posttraumatic stress disorder and the risk of traumatic deaths among Vietnam veterans. J Nerv Ment Dis 1994;82(11):604-10.

[7] Chen YW, Dilsaver SC. Lifetime rates of suicide attempts among subjects with bipolar and unipolar disorders relative to subjects with other axis I disorders. Biol Psychiatry 1996;39:896-9.

[8] Dahl S, Mutapcic A, Schei B. Traumatic events and predictive factors for posttraumatic symptoms in displaced Bosnian women in a war zone. J Trauma Stress 1998; $11: 137-45$

[9] Davidson JRT, Hughes DC, Blazer DG, George LK. Posttraumatic stress disorder in the community: an epidemiological study. Psychol Med 1991:21(3):713-21.

[10] Eurostat. Population Statistics. 2004 ed. Office for Official Publications of the European Communities, 2004.

[11] Floen SK, Elklit A. Psychiatric diagnoses, trauma, and suicidiality. Ann Gen Psychiatry 2007;6:12.

[12] Fontana A, Rosenheck RA. An etiological model of attempted suicide among Vietnam theatre veterans: prospective generalization to a treatment seeking sample. J Nerv Ment Dis 1995;183(6):377-83.

[13] Fontana A, Rosenheck RA. Attempted suicide among Vietnam veterans: a model of etiology in a community sample. Am J Psychiatry 1995;152(1):102-9.

[14] Fullerton CS, Ursano RJ, Epstein RS, Crowley B, Vance KL, Kao TC, et al. Peritraumatic dissociation following motor vehicle accidents: relationship to prior trauma and prior major depression. J Nerv Ment Dis 2000;188: 267-72.

[15] Kessler RC, Berglund P, Borges G. Trends in suicide ideation, plans, gestures, and attempts in the United States, 1990-1992 to 2001-2003. JAMA 2005;293(20):2487-95

[16] Kessler RC, Galea S, Gruber MJ, Sampson NA, Ursano RJ, Wessely SC. Trends in mental illness and suicidality after Hurricane Katrina. Mol Psychiatry 2008;13(4):374-84.

[17] Knox KL. Epidemiology of the relationship between traumatic experience and suicidal behaviors. PTSD Res Q 2008;19(4):1-7.

[18] Kramer TL, Lindy JD, Green BL, Grace MC, Leonard AC. The comorbidity of posttraumatic stress disorder and suicidality in Vietnam veterans. Suicide Life Threat Behav 1994;24(1):58-67.

[19] Lecrubier Y, Sheehan DV, Weiller E, Amorim P, Bonora I, Sheehan KH, et al. The Mini International Neuropsychiatric Interview (MINI). A short diagnostic structured interview: reliability and validity according to the CIDI. Eur Psychiatry 1997;12(5):224-31.

[20] Lipsicas CB, Makinen IH, Apter A, De Leo D, Kerkhof A, Lonnqvist J, et al. Attempted suicide among immigrants in European countries: an international perspective. Soc Psychiatry Psychiatr Epidemiol 2012;47(2):241-51.

[21] Loncar M, Medved V, Jovanovic N, Hotujac L. Psychological consequences of rape on women in 1991-1995 war in Croatia and Bosnia and Herzegovina. Croat Med J 2006;47:67-75.

[22] Mufti KA, Naeem F, Chaudry HR, Haroon A, Saifi F, Qureshi SM, et al. Posttraumatic stress disorder among Afghan refugees following war. Int Psychiatry 2007;4(1):7-9.

[23] Nelson EC, Heath AC, Madden PAF, Cooper ML, Dinwiddie SH, Bucholz KK, et al. Association between self-reported childhood sexual abuse and adverse psychosocial outcomes: results from a twin study. Arch Gen Psychiatry 2002;59(2):139-45.

[24] Panagioti M, Gooding P, Tarrier N. Posttraumatic stress disorder and suicidal behavior: a narrative review. Clin Psychol Rev 2009;29(6):471-82.

[25] Priebe S, Bogic M, Ajdukovic D, Franciskovic T, Galeazzi GM, Kucukalic A, et al. Mental disorders following war in the Balkans: a study in 5 countries. Arch Gen Psychiatry 2010;67(5):518-28.

[26] Priebe S, Bogic M, Ashcroft R, Franciskovic T, Galeazzi GM, Kucukalic A, et al. Experience of human rights violations and subsequent mental disorders- $A$ study following the war in the Balkans. Soc Sci Med 2010;71(12):2170-7.

[27] Priebe S, Gavrilovic Jankovic J, Schuetzwohl M, Galeazzi GM, Lecic-Tosevski D, Ajdukovic D, et al. A study of long-term clinical and social outcomes after war experiences in ex-Yugoslavia - Methods of the 'CONNECT' project. Psych Today 2004;36(1):101-22.

[28] Rossi A, Alberio R, Porta A, Sandri M, Tansella M, Amaddeo F. The reliability of the Mini International Neuropsychiatric Interview: Italian version. J Clin Psychopharmacol 2004;24(5):561-3.

[29] Scholte WF, Olff M, Ventevogel P, de Vries GJ, Jansveld E, Cardozo BL, et al. Mental health symptoms following war and repression in eastern Afghanistan. JAMA 2004;292:585-93.

[30] Sheehan DV, Lecrubier Y, Harnett-Sheehan K, Janavs J, Weiller E, Bonora LI, et al. Reliability and validity of the Mini International Neuropsychiatric Interview (MINI): according to the SCID-P. Eur Psychiatry 1997;12(5):232-41.

[31] Sheehan DV, Lecrubier Y, Sheehan KH, Amorim P, Janavs J, Weiller E, et al. Mini International Neuropsychiatric Interview (MINI): the development and validation of a structured diagnostic psychiatric interview for DSM-IV and ICD-10. J Clin Psychiatry 1998;59(Suppl. 20):22-33.

[32] Southwick SM, Morgan CA, Nicolaou AL, Charney DS. Consistency of memory for combat-related traumatic events in veterans of operation desert storm. Am J Psychiatry 1997;154(2):173-7.

[33] Spasojevic J, Heffer RW, Snyder DK. Effects of posttraumatic stress and acculturation on marital functioning in Bosnian refugee couples. J Trauma Stress 2000;13:205-17.

[34] StataCorp. Stata Statistical Software: Release 10. College Station, TX: StataCorp LP, 2007.

[35] Steel Z, Silove DM, Phan T, Bauman A. Long-term effect of psychological trauma on the mental health of Vietnamese refugees resettled in Australia: a population-based study. Lancet 2002;360(9399):1056-62.

[36] Thoresen S, Mehlum L. Traumatic stress and suicidal ideation in Norwegian male peacekeepers. J Nerv Ment Dis 2008;196:814-21.

[37] Weissman MM, Bland RC, Canino GJ, Greenwald S, Hwu HG, Joyce PR, et al. Prevalence of suicide ideation and suicide attempts in nine countries. Psychol Med 1999;29(1):9-17.

[38] Wenzel T, Rushiti F, Aghani F, Diaconu G, Maxhuni B, Zitterl W. Suicidal ideation, posttraumatic stress and suicide statistics in Kosovo. An analysis five years after the war. Suicidal ideation in Kosovo. Torture 2009;19(3): 238-47.

[39] Williams JMG. Cry of pain. Harmondsworth: Penguin; 1997.

[40] Williams JMG, Crane C, Barnhofer T, Duggan D. Psychology and suicidal behaviour: elaborating the entrapment model. In: Hawton K, editor. Prevention and treatment of suicidal behaviour: from science to practice. Oxford: OUP; 2005. p. 71-89.

[41] Wolfe J, Kimerling R. Gender issues in the assessment of posttraumatic stress disorder. In: Solomon SD, Wilson J, Keane TM, editors. Assessing psychological trauma and PTSD. New York: Guilford Publications; 1997. p. 192-238.

[42] World Health Organisation. Suicide rates per 100,000. 2011. http:// www.who.int/mental_health/prevention/suicide_rates/en/index.html.

[43] Zhang J, Kai YF. What's the relative risk? A method of correcting odds ratio in cohort studies of common outcomes. JAMA 1998;280:1690-1. 